\title{
Concern for Group Reputation Increases Prosociality in Young Children
}

Psychological Science 2018, Vol. 29(2) 181-190 (C) The Author(s) 2017 Reprints and permissions sagepub.com/journalsPermissions.nav DOI: $10.1177 / 0956797617733830$ www.psychologicalscience.org/PS @SAGE

\author{
Jan M. Engelmann', Esther Herrmann ${ }^{1}$, and \\ Michael Tomasello ${ }^{1,2}$ \\ ${ }^{1}$ Department of Developmental and Comparative Psychology, Max Planck Institute for Evolutionary \\ Anthropology, Leipzig, Germany, and ${ }^{2}$ Department of Psychology and Neuroscience, Duke University
}

\begin{abstract}
The motivation to build and maintain a positive personal reputation promotes prosocial behavior. But individuals also identify with their groups, and so it is possible that the desire to maintain or enhance group reputation may have similar effects. Here, we show that 5-year-old children actively invest in the reputation of their group by acting more generously when their group's reputation is at stake. Children shared significantly more resources with fictitious other children not only when their individual donations were public rather than private but also when their group's donations (effacing individual donations) were public rather than private. These results provide the first experimental evidence that concern for group reputation can lead to higher levels of prosociality.
\end{abstract}

\section{Keywords}

cooperation, reputation, group reputation, open data

Received 8/17/16; Revision accepted 8/14/17

Humans actively choose collaborative partners on the basis of characteristics relevant to cooperation, such as prosociality, trustworthiness, and fairness (Nowak \& Sigmund, 1998; Sterelny, 2012; Tomasello, 2016). In much the same way that partner choice in the context of sexual selection creates adaptive pressures to present oneself as an attractive mate, partner choice in the context of cooperation creates selective-and potentially species-unique-pressure to present oneself as prosocial, trustworthy, and fair (Baumard, Andre, \& Sperber, 2013; Engelmann, Herrmann, \& Tomasello, 2012; Gintis, Smith, \& Bowles, 2001). The need to be chosen as a cooperative partner prompts concern for one's reputation along these dimensions and in turn drives the exceptionally high levels of cooperation observed in humans (Fehr, 2004; Krasnow, Cosmides, Pedersen, \& Tooby, 2012; McElreath et al., 2003; Raihani \& Smith, 2015; Rand \& Nowak, 2009; Tennie, Frith, \& Frith, 2010). In experimental settings and natural contexts alike, humans act more prosocially (Soetevent, 2005), donate more to public goods (Milinski, Semmann, \& Krambeck, 2002), show greater rule adherence (Bateson, Callow, Holmes, Redmond Roche, \& Nettle, 2013; Nettle, Nott, \& Bateson, 2012), and are more likely to punish rule violators (Jordan, Hoffman, Bloom, \& Rand, 2016) when their actions are public and their reputations are at stake. The interplay between advertising oneself as a valuable partner and being recruited for collaboration depends on being identifiable and possessing a publically recognized reputation for cooperative behavior.

These two requirements for maintaining a system of partner choice and reputation management work well in smaller social constellations, but can they be met in large-scale communities, where ephemeral exchanges are common, interaction partners are often unidentifiable, and repeated encounters are rare? In other words, does reputation lose its relevance as a mechanism stabilizing cooperation in contexts where agents are unlikely to possess information about the reputation of potential collaborative partners (Dixit, 2004; Henrich et al., 2010; Panchanathan \& Boyd, 2003)? While the influence of an individual's personal reputation may be

\section{Corresponding Author:}

Jan M. Engelmann, Max Planck Institute for Evolutionary Anthropology, Deutscher Platz 6, 04103 Leipzig, Germany E-mail: jan_engelmann@eva.mpg.de 
reduced in such contexts, humans often selectively interact with some partners on the basis of their association with, or membership in, certain groups, institutions, or organizations. In situations where a potential partner's cooperative profile is inaccessible, the reputation of the larger body the potential partner is associated with may serve as a proxy for individual reputation. This occurs, for example, when one selectively visits and trusts a doctor who displays a Harvard Medical School certificate over a doctor who attended a less prestigious university, or when one entrusts money to a banker who works for a responsible and reliable financial institution over a banker who represents a bank with a reputation for greed and illegal practices. One may then posit that if partner choice on the individual level leads to agents caring about their individual reputation, partner choice based on group or institutional affiliation should lead to individuals caring about the reputation of their group.

The observation that humans selectively interact with some individuals over others on the basis of their membership in certain groups, and thus engage in "group choice" or "institution choice," is supported by experimental research. In economic games, humans selectively choose some groups or institutions over others: Gürerk, Irlenbusch, and Rockenbach (2006) have recently shown that "institutional selection" can play a role in the emergence of human cooperation. In their study, participants could choose whether to interact with partners who were members of sanctioning institutions or partners who were affiliated with institutions that lacked punitive devices. Their results show that participants reliably chose and migrated to sanctioning institutions and that the possibility of institutional selection increased levels of cooperation. Thus, examples drawn from common experiences and experimental research indicate that humans engage in group or institutional choice and selectively interact with some partners over others on the basis of their membership in certain groups. However, it is unknown whether humans show a corresponding concern for their group's reputation and whether this concern motivates individuals to act cooperatively.

It is well established that the need to build and maintain a good individual reputation can have positive effects on various measures of cooperation in humans (Fessler, 2007). Indeed, recent research has shown that concern for individual reputation emerges early in ontogeny and promotes cooperation in children as young as 5 years old (Martin \& Olson, 2015). Children at this age consider a positive reputation desirable and act in prosocial ways to maintain their individual reputation (Fu, Heyman, Quian, Guo, \& Lee, 2015). For example, preschoolers consistently choose a generous option only when a peer recipient is fully aware of the identity of the donor and the different options available to the donor (Leimgruber, Shaw, Santos, \& Olson, 2012). Similarly, and as further evidence for children's burgeoning sense of such "strategic prosociality," SebastiánEnesco and Warneken (2015) found that 5-year-old children, but not 3-year-old children, adjust their levels of prosociality on the basis of the likelihood of future interaction (see also Blake, Rand, Tingley, \& Warneken, 2015). Finally, and perhaps most relevant to the current study, Engelmann et al. (2012) have shown that young children behave more prosocially-they steal less and help more-when they are in the presence of a peer observer than when they are alone. Interestingly, young children not only differentiate situations on the basis of whether they are observed or not but also show sensitivity to who is observing them; in-group members and potential reciprocators evoke greater reputational concern than out-group members (Engelmann, Over, Herrmann, \& Tomasello, 2013). While we know from these studies that young children care about their individual reputation, to our knowledge no previous study has investigated to what extent concern for group reputation can foster prosociality.

\section{Study 1}

We investigated the existence of a concern for group reputation and its positive effects on levels of prosociality in a laboratory study with 5 -year-old children. In our experiment, groups of 3 children each were assigned to the same group (the "yellow group") using a minimal group paradigm (Billig \& Tajfel, 1973; Dunham, Baron, \& Carey, 2011). Children were each handed 10 toys and told that if they wanted to, they could share any number of toys with children from a different kindergarten. While they distributed their toys, participants were observed by two peers. At the end of the procedure, children pushed their donations into a donation box, and we systematically manipulated whether observers could see what children had donated to the other kindergarten. Specifically, we varied (a) group reputation-that is, whether the group's combined donation was public or private-and (b) individual reputation - that is, whether children's individual donations were public or private.

\section{Metbod}

Participants. We tested 96 children in groups of three each (age range $=60$ months, 3 days, to 70 months, 30 days; mean age $=66$ months, 15 days; 48 females) in a quiet room in their day-care centers. Twenty-four subjects participated in each condition. ${ }^{1}$ The sample size was 
specified a priori on the basis of previous research that used a similar design and procedure (Engelmann et al., 2013). Eleven additional groups had to be excluded: eight because one of the children mentioned how many toys she intended to share, one because the video camera did not work, one because of experimenter error, and one because participants had to leave for sports class.

Each group was observed by two peers, one of the same and one of the opposite gender. Ninety-four additional children acted as observers (age range $=60$ months, 20 days, to 86 months, 21 days; mean age $=74$ months, 15 days; 45 females). Observers participated in multiple trials. Furthermore, for each group, one child participated during the group assignment only as member of the nontested "red group." Seventy-nine additional children participated as red-group members (age range $=60$ months, 9 days, to 81 months, 13 days; mean age $=67$ months, 16 days; 38 females). These children participated in multiple trials. Finally, for the only-individual-public condition, 48 additional children participated in the study (age range $=60$ months, 10 days, to 81 months, 14 days; mean age $=68$ months, 14 days; 24 females), and their data were not recorded (they acted as the two "private" children whose donations were not visible to observers).

Children were tested in a quiet room in their daycare centers. Participants, observers, and children for the nontested group (see the Group Manipulation section) were all familiar with each other because they were recruited from the same day-care groups or from groups that frequently interacted with one another.

Materials. Each participant stood in one compartment that formed part of a large donation box $(149 \times 40 \times 90$ $\mathrm{cm}$; see Fig. 1). To make sure that participants could not see each other, we separated compartments by dividing

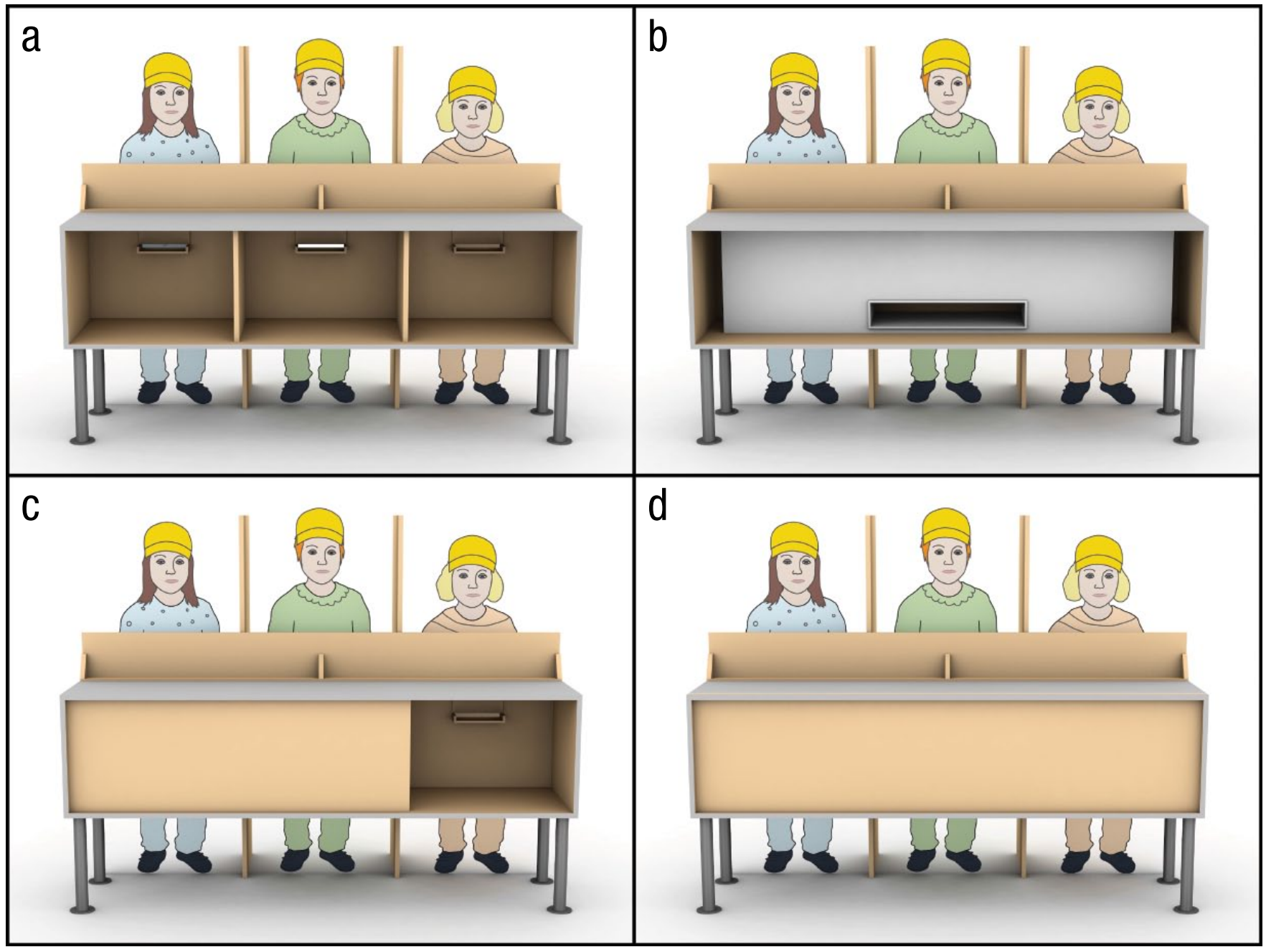

Fig. 1. Experimental setup in the four conditions of Study 1: (a) both public, (b) only group public, (c) only individual public, and (d) both private. The no-group condition (Study 2) was identical to the only-group-public condition in Study 1, except that children were not assigned to a group. 
walls $(60 \times 127 \mathrm{~cm})$. Participants received 10 small plastic eggs, each containing a toy. These could be placed either in a drawer $(15 \times 14 \times 9 \mathrm{~cm})$ that was connected to the box or in a waist pack that the children were carrying. The materials for the groups were hooded sweaters, caps, and waist packs. There were two sets of these group markers, one yellow and one red.

Design. A $2 \times 2$ design allowed us to isolate the impact of concern for group reputation and concern for individual reputation on levels of prosociality. Group reputation and individual reputation could be either public or private. In public conditions, the two peer observers could see donations through transparent windows in the donation box, whereas donations in private conditions were not visible to observers because the windows were opaque.

Children participated in one trial in one of the four conditions. In the both-public condition, observers could see how much the yellow group had donated in total as well as how much each individual had donated (Fig. 1a). In the only-group-public condition, observers could see only how much the yellow group had donated but not how much each individual had contributed. This was achieved by adding a structure to the donation box that mixed individual donations before they appeared as one entity (Fig. 1b). In the only-individual public condition, observers could not see how much the yellow group had donated but could see how much one target individual had donated (Fig. 1c). Only the data of the target individual were recorded in this condition. Finally, in the both-private condition, observers could not see how much the group or any individual had donated (Fig. 1d).

Procedure. Six children participated in one trial: three same-sex participants, one additional child for the nontested group (same sex as the participants), and two observers ( 1 female, 1 male). Children were randomly assigned to their respective roles.

Group manipulation. At the beginning of each trial, two experimenters (Experimenter 1 and Experiment 2) entered the room with the three participants and the child for the nontested group (Experimenter 3 waited outside with the two observers). The four children were told that they had to stand next to each other because they would be told something important by Experimenter 1. Experimenter 1 then told the participants that there were two different groups in the game they would now be playing: yellow and red. Then Experimenter 1 appeared to randomly draw (with his eyes closed) a yellow or red sweater from an opaque box for each of the four children. This was fixed such that three children would be assigned to the yellow group and one child to the red group. Each child then received a baseball cap followed by a waist pack, each matching his or her group color. Next, Experimenter 1 told the children that the yellow group could play first, and so Experimenter 2 left with the child who had been assigned to the red group. We were not interested in the behavior of the redgroup member but included this additional child only to highlight the existence of a second group.

Introduction to the sharing game. Once Experimenter 2 and the red-group member had left the room, Experimenter 1 drew the children's attention (they were now addressed as "the yellow group") to the donation box (see Fig. 1). Experimenter 1 assigned each child to one compartment and told the children that everything that was placed in the drawers would end up in the donation box. Furthermore, Experimenter 1 explained that the contents of the donation box would later be given to children from a different kindergarten. Experimenter 1 also told the children that since the drawers could not be reopened once they had been shut, they should be closed only at the end, once Experimenter 1 rang a toy bell. Experimenter 1 then showed the toy bell to the children and rang it.

Experimenter 1 asked the three participants to join him in front of the box, pointed at the front of the box, and told the children either that they could look into the box (public conditions) or that they could not look into the box (private conditions). Once each participant returned to his or her respective compartment, Experimenter 1 handed each child 10 plastic eggs and told the children that each egg contained one toy (Experimenter 1 showed the children one sample toy). Experimenter 1 added that the children could take all the eggs home but that they should be opened only at the end. The children were then told to place the toys they wanted to take home in their waist pack and that, should they wish to, they could also share some of their toys with a different kindergarten by placing them in the drawer connected to the box.

Experimenter 1 then pointed to two chairs that were positioned at a distance of $2.5 \mathrm{~m}$ from the donation box and told the participants that two children would sit there later. Experimenter 1 asked each child, one after the other, to sit down with him on the chairs. Each participant was then asked two questions: whether the observers would be able to see how much he or she (i.e., the participant) had placed in the donation box and how much the yellow group had placed in the donation box in total. The correct answer to the first question was "yes" in conditions where individual reputation was public and "no" in conditions where it was private. Likewise, children were coded as answering 
the second question correctly if they said "yes" in conditions where group reputation was public and "no" in conditions where it was private. If children failed to answer the questions, Experimenter 1 told the children to look at the donation box once more and then asked again. All children answered the questions correctly after one repetition.

Playing the sharing game. Once each participant again stood in his or her respective compartment, Experimenter 1 fetched the two observers, who were waiting outside the testing room, and asked them to sit down on the chairs. The group membership of the two observers was neutral; that is, they were not assigned to a minimal group. At this point, Experimenter 1 checked whether participants had understood the instructions and asked each child separately where to place the toys they wanted to take home and where to place the toys for the other kindergarten. If a participant failed this check, the instructions were repeated to that participant, and he or she was asked again. Experimenter 1 then told the five children that this was a "silent game" and that they should not engage in conversation with each other. Finally, Experimenter 1 stated that he had to write down something important and told them to start. Experimenter 1 retreated to a corner of the testing room and turned his back to the children. After $30 \mathrm{~s}$, Experimenter 1 asked the children whether they were finished and gave them more time if they needed it. Once all children were finished, Experimenter 1 rang his bell, and the three participants closed their drawers.

At the end of the procedure, Experimenter 1 left the testing room with the five children. Experimenter 2 then entered the room with each participant separately and asked him or her a control question-namely, whether the observers could see how many toys the child had donated to the other kindergarten. This question was asked in all conditions, but we were especially interested in children's responses in the only-group-public condition since we wanted to inquire whether children had understood that their individual donations were not visible to the observers in this condition; $91.7 \%$ of the children answered the question correctly. Finally, Experimenter 2 filmed the number of toys in each child's waist pack to infer how many toys each participant had shared (since in the both-private and onlygroup-public conditions, individual donations could not be inferred from the donation box). Once this had been done, the child who was a member of the red group was allowed to distribute 10 toys as well.

Coding and analysis. The number of toys given to the other kindergarten was coded from tape by the first experimenter and the first author. A research assistant, who was unaware of the study design and hypothesis, independently coded $25 \%$ of all trials. Interrater agreement was excellent (Cohen's $\kappa=1$ ).

\section{Results}

Figure 2 presents the number of toys donated in the four conditions of our $2 \times 2$ design. The average numbers of toys donated were 5.7 (both-public condition), 5.8 (only-group-public condition), 5 (only-individualpublic condition), and 3.4 (both-private condition).

To test the effects of group reputation and individual reputation (and their potential interaction) on children's sharing behavior, we used a generalized linear model, which we fitted with negative binomial error structure and log link function (McCullagh \& Nelder, 2008). We additionally controlled for gender. To establish the significance of the full model (Schielzeth \& Forstmeier, 2009), we used a likelihood-ratio test (Dobson, 2002), comparing its deviance with that of the null model containing only gender and the intercept. To test the significance of the interaction between group reputation and individual reputation, we compared the full model's deviance with that of a corresponding reduced model not containing the interaction. The model was fitted in R (R Core Team, 2015) using the function glm .nb of the package MASS (Venables \& Ripley, 2002).

Overall, the full model was highly significant compared with the null model-likelihood-ratio test: $\chi^{2}(3)=16.08, p=.001$. Specifically, we found an interaction between group reputation and individual reputation (estimate $=-0.401, S E=0.200), \chi^{2}(1)=4.060$, $p=.045,95 \%$ confidence interval $(\mathrm{CI})=[-0.793,-0.010]$. For the model output, refer to the Supplemental Material available online. To further investigate the interaction between group reputation and individual reputation, we conducted post hoc pairwise comparisons. ${ }^{2}$ We found a significant difference between the only-group-public and the both-private conditions $(p<$ .001 ), showing that children were more generous when donations of the group were public-even though individual contributions were unknown. We also found a significant difference between the only-individualpublic and the both-private conditions $(p=.009)$, which indicated that children donated more toys when individual contributions were public. There was no difference when comparing the only-group-public and the both-public conditions $(p=.959)$ and when comparing the only-individual-public and the both-public conditions $(p=.309)$. There were no changes in significance levels when the $8 \%$ of children who did not answer the control question correctly (see the Procedure section) were excluded from the sample. 


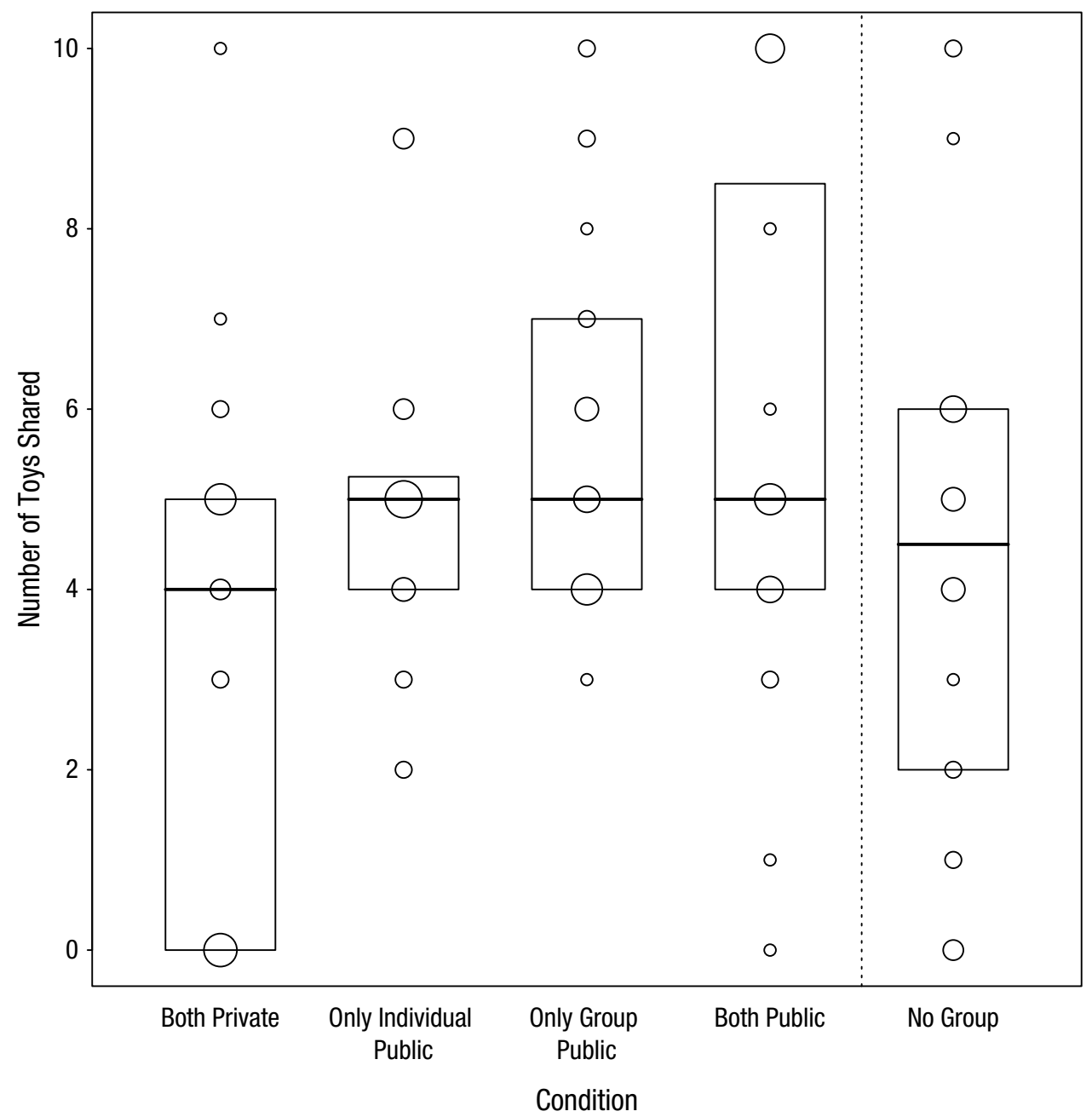

Fig. 2. Results from Studies 1 and 2: mean number of toys donated by children in the four conditions of Study 1 (both private, only individual public, only group public, and both public) and the one condition of Study 2 (no group). Data points are depicted by dots, with bigger dots representing more data points. Each box represents 25 th and 75 th percentiles. Horizontal lines within boxes represent medians.

\section{Discussion}

Study 1 provides evidence that young children care not only about their individual reputation but also about the reputation of their group and that this concern for group reputation can positively influence their prosociality. However, it is unclear whether children's behavior in the crucial condition-the only-group-public condition-was motivated only by concern for their group's reputation. An alternative is that children's increased prosociality in this condition is rooted in concern for individual reputation. Indeed, some outcomes might have allowed observers to make inferences about individual contributions. For example, children might have reasoned that if they do not share anything and their peers do not share anything either, then the two observers would know how much they shared. Study 2 tested these different alternatives.

\section{Study 2}

Study 2 introduced a new condition-the no-group condition-which was identical to the only-grouppublic condition in Study 1, except that children were not assigned to a minimal group. Thus, in this condition, observers could see how much three childrenwho were not assigned to the same group-had donated in total but not how much each individual had contributed.

\section{Metbod}

Participants. We tested 24 children (age range $=61$ months, 17 days, to 70 months, 29 days; mean age $=66$ months, 12 days; 12 females) in groups of three each (each subject participated in the study with two confederates). Five additional children had to be excluded 
because confederates mentioned how many toys they were going to share ( 4 children), and 1 child did not want to continue playing the game.

In total, 30 children acted as confederates (age range $=62$ months, 27 days, to 82 months, 8 days; mean age $=67$ months, 12 days; 15 females). Confederates participated in multiple trials. Each group was observed by two peers, one of the same and one of the opposite gender. Twenty-eight additional children acted as observers (age range $=60$ months, 1 day, to 66 months, 8 days; mean age $=64$ months, 6 days; 14 females). Observers participated in multiple trials. Children were randomly assigned to the participant, confederate, or observer role.

Procedure. There was one condition (the no-group condition) in this study, and the procedure was identical to that in the other conditions, except for two modifications. First, given that children were not assigned to a minimal group in this condition, there was no group manipulation. Second, since we wanted to minimize the possibility of participants developing a sense of group membership as a result of engaging in the same task, participants were introduced to the sharing game individually and not in groups of three. Furthermore, since we wanted to avoid some participants having to wait longer than others before starting the sharing task (introduction to the task took about $15 \mathrm{~min}$ ), each subject participated in the game with two same-sex and same-age confederates who were recruited from the same day-care centers. Thus, the overall sequence of this condition was as follows. First, Experimenter 1 introduced the two confederates to the task and told them that later in the game they should put five toys in the drawer and five toys in their waist pack (theoretically, confederates could have distributed toys in any way they wished since participants could neither see nor hear their distribution, but we wanted to give them clear directions). Then, Experimenter 1 introduced the participant to the task (this was identical to the familiarization in the other conditions). From this point, the procedure was the same as in Experiment 1 (i.e., from the section "Playing the Sharing Game" onward); all three children were in the room together, and the procedure was the same as in all other conditions.

\section{Results}

In the no-group condition, children shared on average 4.3 toys (see Fig. 2). To compare the number of toys shared in this condition with the number of toys shared in the only-group-public condition of Study 1, we used a generalized linear model, which we fitted with negative binomial error structure and log link function (McCullagh \& Nelder, 2008). The model was fitted in R
(R Core Team, 2015) using the function glm.nb of the package MASS (Venables \& Ripley, 2002). We found a significant difference between the two conditions, indicating that children shared more toys in the only-grouppublic condition (estimate $=-0.298, S E=0.135), \chi^{2}(1)=$ $5.495, p=.027,95 \% \mathrm{CI}=[-0.563,-0.034]$. There was no difference when comparing the no-group condition to the both-private condition (estimate $=0.274, S E=$ $0.229), \chi^{2}(1)=1.425, p=.233,95 \% \mathrm{CI}=[-0.185,0.726]$.

\section{Discussion}

Study 2 shows that children's increased donations in the only-group-public condition were due to concern for group reputation. The fact that children gave more toys in a condition where group reputation was at stake (only-group-public condition) compared with the exact same condition without a group manipulation (nogroup condition) suggests that children care about and actively invest in the reputation of their group.

\section{General Discussion}

Our results show that young children care about the reputation of their group and that this concern positively influences levels of prosociality. When the reputation of their group was at stake, young children were motivated to invest in their group's reputation by selectively increasing their prosociality-even when individual contributions were anonymous and prosocial deeds could not be attributed to any child individually. Specifically, when 5-year-old preschoolers acted from within an assigned group and that group's combined donation was public, they shared more toys with children from a different kindergarten compared with a situation in which the collective donation remained private. Notably, this effect was observed using a minimal group paradigm in which children were assigned to novel social groups with which they had no previous experience.

We also found that young children care about and invest in their individual reputation. When contributions could be traced back to each individual, children shared significantly more of their own toys than when personal donations were private. This result corroborates previous work on young children's concern for reputation (Engelmann et al., 2013; Fu et al., 2015; Leimgruber et al., 2012). From at least the age of 5 onward, young children show a robust tendency to care about the impressions they make on others coupled with a motivation to invest in a reputation as a prosocial person.

This raises the question as to the relationship between concern for individual reputation and concern for group reputation. There is no doubt that individuals 
often benefit from being members of groups, institutions, or organizations that have good reputations. That is to say, belonging to a group with a positive reputation can have welcome consequences for individual reputation-especially in cases where group reputation is taken as a proxy for individual reputation. To return to the example from the introduction, this might include a doctor being chosen on the basis of his or her degree from a prestigious university and not because of his or her individual reputation. The question is whether the concern of individuals for group reputation is, motivationally speaking, separate from and irreducible to their tendency to manage individual reputation. Results of the present studies suggest that concern for group reputation is distinct from concern for individual reputation. In Study 1, in the most relevant condition (only group public), the groups' overall donation was public, whereas children's individual donations were anonymous. Children were aware that their individual contributions were unknown to the observers in this condition; in fact, more than $90 \%$ of participants correctly stated so in response to our control question. Nevertheless, children proved significantly more generous in this condition than in a condition where both group and individual donations were private (bothprivate condition). However, it is possible that children's increased donations in the only-group-public condition can be explained in terms of concern for individual reputation. ${ }^{3}$ Study 2 tested this alternative explanation by comparing the only-group-public condition with an additional condition, the no-group condition. In both conditions, the combined output of three children was visible to observers (and individual input was unknown), but group reputation was at stake only in the only-group-public condition (since children were not assigned to the same group in the no-group condition). Children shared significantly more toys in the only-group-public condition than in the no-group condition. It would thus seem that children's concern for group reputation is not reducible to concern for individual reputation. This is not to say that investment in group reputation provides evidence for any form of group-level selection mechanisms. Ultimately, individuals probably evolved to care about the reputation of their group because of the positive effects on individual reputation. But this does not mean that the proximate mechanism cannot be a genuine concern for the reputation of one's group that is, at least to some extent, independent of concern for individual reputation.

Developing a thorough understanding of the interplay between individual and group reputation is an exciting avenue for future research. One approach would be to study experimental contexts in which actions that benefit one of the forms of reputation (group or individual) result in negative effects on the other form of reputation. For example, would individuals act in ways that advance their group's reputation even if doing so would simultaneously diminish their individual reputation?

This is the first study to show that concern for group reputation can increase prosociality-even in children as young as 5 years old. Our findings demonstrate that levels of prosociality not only vary as a function of whether individual reputation is at stake but also are based on whether group reputation is affected by one's actions. Previous work has shown that concern for individual reputation can stabilize cooperation in groups featuring a manageable pool of potential collaborators (for a review, see Milinski, 2016). The current results build on and extend this line of research by showing that concern for group reputation promotes prosociality, thus potentially suggesting a mechanism that can positively influence levels of cooperation in larger communities. Modeling mechanisms of large groups, institutions, or organizations in experimental contexts is far from straightforward, and one limitation of the current study is that we used fairly small groups consisting of three children. In larger groups, individuals can more easily submerge into the anonymity of their group and, as a result, have more opportunities to "free-ride" on the efforts of others (Boyd \& Richerson, 1989; Henrich, 2015). However, although our experimental groups were smaller than most natural groups, we believe that our design captures the crucial aspect of such situations: Group output is public, but individual contribution is not, creating an incentive to exploit others' efforts in building and maintaining the group's reputation.

In contexts where information about individual reputations is not easily accessible, the reputation of the group or institution that we are associated with-the university where we studied, the company for which we work, the organization of which we are a membercan serve as a proxy for individual reputation. This creates pressure to care about and invest in the reputation of one's group. Here, we have shown that 5-yearold children show concern for group reputation and selectively act more prosocially when their group's reputation is at stake.

\section{Action Editor}

Steven W. Gangestad served as action editor for this article.

\section{Author Contributions}

J. M. Engelmann, E. Herrmann, and M. Tomasello designed the study, analyzed the data, and wrote the manuscript. 


\section{Acknowledgments}

We thank Katharina Haberl, Jana Jurkat, Felix Hajduk, Esther Klonowski, Georg Keller, and Manuela Pauli for their help in testing the children. Special thanks go to Roger Mundry and Colleen Stephens for statistical advice and to Silvio Tuepke for Figure 1. We also thank Sinja Thielicke for reliability coding. Finally, we thank Felix Warneken, Anna-Claire Schneider, Diotima Rapp, Harriet Over, and Sebastian Grüneisen for very helpful comments on previous versions of this manuscript.

\section{Declaration of Conflicting Interests}

The authors declared that they had no conflicts of interest with respect to their authorship or the publication of this article.

\section{Supplemental Material}

Additional supporting information may be found at http:// journals.sagepub.com/doi/suppl/10.1177/0956797617733830

\section{Open Practices}

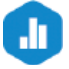

All data have been made publicly available via the Open Science Framework and can be accessed at https://osf.io/ wgfnm/. The complete Open Practices Disclosure for this article can be found at http://journals.sagepub.com/doi/suppl/ 10.1177/0956797617733830. This article has received the badge for Open Data. More information about the Open Practices badges can be found at http://www.psychologicalscience.org/ publications/badges.

\section{Notes}

1. In the only-individual-public condition, we tested 24 groups of 3 children each because the data of only one individual were recorded (the "public" individual). In each of the three other conditions, we tested eight groups of 3 children each.

2. The $p$ values for the pairwise comparisons were obtained from Wald $Z$ approximation on the basis of estimates and standard errors revealed by the model. Two of the four comparisons were obtained after releveling the factors of individual condition and group condition.

3. Think of the following situation, which is, at least in some ways, analogous to our only-group-public condition. You are out for dinner with people who you do not like very much. You know these people to be stingy tippers, so at the end of dinner, you leave a significantly larger tip than you normally wouldnot because you care about the reputation of this group (you do not like the group), but because you know that leaving a small tip can have negative consequences for your individual reputation. If everyone else leaves a small tip and you do, too, then everyone will know that you left a small tip. We thank an anonymous reviewer for this poignant example.

\section{References}

Bateson, M., Callow, L., Holmes, J. R., Redmond Roche, M. L., \& Nettle, D. (2013). Do images of 'watching eyes' induce behaviour that is more pro-social or more normative? A field experiment on littering. PLOS ONE, 8(12), Article e82055.

Baumard, N., Andre, J.-B., \& Sperber, D. (2013). A mutualistic approach to morality: The evolution of fairness by partner choice. Behavioral \& Brain Sciences, 36, 59-122.

Billig, M., \& Tajfel, H. (1973). Social categorization and similarity in intergroup behaviour. European Journal of Social Psychology, 3, 27-52. doi:10.1002/ejsp.2420030103

Blake, P. R., Rand, D. G., Tingley, D., \& Warneken, F. (2015). The shadow of the future promotes cooperation in a repeated prisoner's dilemma for children. Scientific Reports, 5, 14559. doi:10.1038/srep14559

Boyd, R., \& Richerson, P. J. (1989). The evolution of indirect reciprocity. Social Networks, 11, 213-236. doi:10.1016/0378-8733(89)90003-8)

Dixit, A. K. (2004). Lawlessness and economics: Alternative modes of governance. Princeton, NJ: Princeton University Press.

Dobson, A. J. (2002). An introduction to generalized linear models (2nd ed.). Boca Raton, FL: Chapman \& Hall/CRC.

Dunham, Y., Baron, A. S., \& Carey, S. (2011). Consequences of "minimal" group affiliations in children. Child Development, 82, 793-811. doi:10.1111/j.1467-8624.2011.01577.x

Engelmann, J. M., Herrmann, E., \& Tomasello, M. (2012). Five-year olds, but not chimpanzees, attempt to manage their reputations. PLOS ONE, 7(10), Article e 48433. doi:10.1371/journal.pone.0048433

Engelmann, J. M., Over, H., Herrmann, E., \& Tomasello, M. (2013). Young children care more about their reputations with ingroup members and potential reciprocators. Developmental Science, 16, 952-958.

Fehr, E. (2004). Don't lose your reputation. Nature, 432, 449-450. doi:10.1038/432449a

Fessler, D. M. T. (2007). From appeasement to conformity: Evolutionary and cultural perspectives on shame, competition, and cooperation. In J. L. Tracy, R. W. Robins, \& J. P. Tangney (Eds.), The self-conscious emotions: Theory and research (pp. 174-193). New York, NY: Guilford Press.

Fu, G., Heyman, G. D., Quian, M., Guo, T., \& Lee, K. (2015). Young children with a positive reputation to maintain are less likely to cheat. Developmental Science, 19, 275-283.

Gintis, H., Smith, E. A., \& Bowles, S. (2001). Costly signaling and cooperation. Journal of Theoretical Biology, 213, 103-119. doi:10.1006/jtbi.2001.2406

Gürerk, Ö., Irlenbusch, B., \& Rockenbach, B. (2006). The competitive advantage of sanctioning institutions. Science, 312, 108-111. doi:10.1126/science. 1123633

Henrich, J. (2015). The secret of our success: How culture is driving human evolution, domesticating our species, and making us smarter. Princeton, NJ: Princeton University Press.

Henrich, J., Ensminger, J., McElreath, R., Barr, A., Barrett, C., Bolyanatz, A., . . . Ziker, J. (2010). Markets, religion, community size, and the evolution of fairness and punishment. Science, 327, 1480-1484. doi:10.1126/science.1182238

Jordan, J. J., Hoffman, M., Bloom, P., \& Rand, D. G. (2016). Third-party punishment as a costly signal of trustworthiness. Nature, 530, 473-476. doi:10.1038/nature16981

Krasnow, M. M., Cosmides, L., Pedersen, E., \& Tooby, J. (2012). What are punishment and reputation for? PLOS ONE, 7(9), Article e45662. doi:10.1371/journal.pone.0045662 
Leimgruber, K. L., Shaw, A., Santos, L. R., \& Olson, K. R. (2012). Young children are more generous when others are aware of their actions. PLOS ONE, 7(10), Article e48292. doi:10.1371/journal.pone.0048292

Martin, A. R., \& Olson, K. R. (2015). Beyond good and evil: What motivations underlie children's prosocial behavior? Perspectives on Psychological Science, 10, 159-175.

McCullagh, P., \& Nelder, J. A. (2008). Generalized linear models. London, England: Chapman \& Hall.

McElreath, R., Clutton-Brock, T. H., Fehr, E., Fessler, D. M. T., Hagen, E. H., Hammerstein, P., . . . Wilson, M. I. (2003). The role of cognition and emotion in cooperation. In P. Hammerstein (Ed.), Genetic and cultural evolution of cooperation (pp. 125-152). Cambridge, MA: MIT Press.

Milinski, M. (2016). Reputation, a universal currency for human social interactions. Philosophical Transactions of the Royal Society B: Biological Sciences, 371(1687), 20150100. doi:10.1098/rstb.2015.0100

Milinski, M., Semmann, D., \& Krambeck, H.-J. (2002). Reputation helps solve the 'tragedy of the commons.' Nature, 415, 424-426. doi:10.1038/415424a

Nettle, D., Nott, K., \& Bateson, M. (2012). 'Cycle thieves, we are watching you': Impact of a simple signage intervention against bicycle theft. PLOS ONE, 7(12), Article e 51738.

Nowak, M. A., \& Sigmund, K. (1998). Evolution of indirect reciprocity by image scoring. Nature, 393, 573-577.

Panchanathan, K., \& Boyd, R. (2003). A tale of two defectors: The importance of standing for evolution of indirect reciprocity. Journal of Theoretical Biology, 224, 115-126. doi:10.1016/s0022-5193(03)00154-1
Raihani, N. J., \& Smith, S. (2015). Competitive helping in online giving. Current Biology, 25, 1183-1186.

Rand, D. G., \& Nowak, M. A. (2009). Name and shame: How reputation could save the earth. New Scientist, 204(2734), 28-29. doi:10.1016/S0262-4079(09)62991-2

R Core Team. (2015). $R$ : A language and environment for statistical computing. Retrieved from http://www.R-project.org

Schielzeth, H., \& Forstmeier, W. (2009). Conclusions beyond support: Overconfident estimates in mixed models. Behavioral Ecology, 20, 416-420. doi:10.1093/beheco/ arn145

Sebastián-Enesco, C., \& Warneken, F. (2015). The shadow of the future: 5-year-olds, but not 3-year-olds, adjust their sharing in anticipation of reciprocation. Journal of Experimental Child Psychology, 129, 40-54. doi:10.1016/j .jecp.2014.08.007

Soetevent, A. R. (2005). Anonymity in giving in a natural context-a field experiment in 30 churches. Journal of Public Economics, 89, 2301-2323. doi:10.1016/j.jpubeco .2004 .11 .002

Sterelny, K. (2012). The evolved apprentice: How evolution made humans unique. Cambridge, MA: MIT Press.

Tennie, C., Frith, U., \& Frith, C. D. (2010). Reputation management in the age of the world-wide web. Trends in Cognitive Sciences, 14, 482-488. doi:10.1016/j.tics .2010 .07 .003

Tomasello, M. (2016). A natural bistory of human morality. Cambridge, MA: Harvard University Press.

Venables, W. N., \& Ripley, B. D. (2002). Modern applied statistics with $S$ (4th ed.). New York, NY: Springer. 